\title{
Serum interleukin-22 (IL-22) is increased in the early stage of Hashimoto's thyroiditis compared to non-autoimmune thyroid disease and healthy controls
}

\author{
Rosaria Maddalena Ruggeri, ${ }^{1}$ Paola Minciullo, ${ }^{2}$ Salvatore Saitta, ${ }^{2}$ Salvatore Giovinazzo, ${ }^{1}$ \\ Rosaria Certo, ${ }^{1}$ Alfredo Campennì, ${ }^{3}$ Francesco Trimarchi, ${ }^{1}$ Sebastiano Gangemi, ${ }^{2}$ \\ Salvatore Benvenga ${ }^{1,4,5}$ \\ ${ }^{1}$ Unit of Endocrinology, ${ }^{2}$ School and Unit of Allergy and Clinical Immunology, Department of Clinical and Experimental \\ Medicine; ${ }^{3}$ Nuclear Medicine Unit, Department of Biomedical Sciences and of Morphological and Functional Images; \\ ${ }^{4}$ Master on Childhood, Adolescent and Women's Endocrine Health; University of Messina; ${ }^{5}$ Interdepartmental Program \\ of Molecular and Clinical Endocrinology \& Women's Health; A.O.U. Policlinico “G. Martino”, Messina, Italy
}

\begin{abstract}
OBJECTIVE: Hashimoto's thyroiditis (HT) is considered to be a Th1-related autoimmune disease (AID). Recent studies revealed that Th17 lymphocytes (producing mostly IL-17, IL-21 and IL-22) play a major role in numerous AIDs commonly thought to be Th1 diseases. More recently, another subset of Th cells, which produce IL-22 and thus so-called Th-22, have been identified. Few data are available in the literature on the role of IL-22, the main soluble mediator of both Th17 and Th22 cells, in HT. DESIGN: Using IL-22 Quantikine ELISA Kit (lower limit of detection $0.7 \mathrm{pg} / \mathrm{ml}$ ), we assayed serum levels of IL-22 in three groups of subjects: newly diagnosed HT patients $(n=55,5$ males and 50 females, age $38 \pm 17$ years $)$, non-HT patients with nodular goiter $(n=30,4$ males and 26 females, age $43 \pm 14$ years) and an age- and sex-matched group of healthy individuals. HT patients were euthyroid and were not receiving any treatment. RESULTS: HT patients showed significantly higher levels of serum IL-22 (group A, $42 \pm 34$ pg/ $\mathrm{ml})$ as compared to non-HT-goitrous patients $(18 \pm 15 \mathrm{pg} / \mathrm{ml} ; \mathrm{P}<0.001)$ and healthy controls $(20 \pm 13 \mathrm{pg} / \mathrm{ml} ; \mathbf{P}=0.014)$. Serum IL-22 levels did not differ between non-HT-goitrous patients and healthy controls $(p=0.496)$. No significant correlation was found between serum levels of IL-22 and Tg-Ab, TPO-Ab or TSH in the HT patients. CONCLUSIONS: Serum IL-22 is increased in newly diagnosed, untreated HT patients, as compared to thyroid autoimmune diseasefree individuals. Our data suggest that IL-22 could play some role in the development of HT.

Key words: Autoimmune thyroid disease, Cytokines, Hashimoto's thyroiditis, Interleukin 22, Lymphocytes T-Helper 17 and 22 (Th17 and Th22)
\end{abstract}

Rosaria Maddalena Ruggeri, MD, PhD, Sezione di Endocrinologia, Dipartimento di Medicina Clinica e Sperimentale, Padiglione H, Policlinico Universitario “G. Martino”, 98125 Messina, Italy, Tel.: +39-090-221.3840; Fax: +39-090-221.3518,

E-mail: rmruggeri@unime.it

Received 24-04-2013, Accepted 10-09-2013 


\section{INTRODUCTION}

Hashimoto's thyroditis (HT) is worldwide the most prevalent autoimmune thyroid disease (AITD) and the main cause of hypothyroidism in iodine-sufficient areas. ${ }^{1,2}$ It represents an archetype for organ-specific autoimmune diseases (AIDs) and is characterized by extensive inflammatory infiltration and destruction of thyroid cells by $\mathrm{CD} 8+$ cytotoxic $\mathrm{T}$ lymphocytes and antibody-mediated immune processes, with help from differentiated CD4+T helper cells (Th). ${ }^{3,4}$ Among the CD4+ Th cells, two functionally distinct subsets have been identified based on their cytokine secretion profiles, namely Type 1 (Th1) and Type 2 (Th2). Th1 cells produce interleukin 2 (IL-2), interferon $\gamma(\mathrm{IFN}-\gamma)$ and lymphotoxin and induce cellular responses. Th2 cells secrete IL-4, IL-5, IL-6, IL-9, IL-10 and IL-13 and promote production of antibodies. ${ }^{3,4} \mathrm{~A}$ third subset of CD4+ cells (Th3 lymphocytes) mainly synthesize TGF- $\beta$ and are considered as a key for the regulation of the adaptive immune response, the so-called regulatory T-cells or Treg. ${ }^{5}$ Tregs play a leading role in developing immune tolerance through active suppression, have anti-inflammatory properties and can enhance quiescence of autoimmune diseases and prolongation of transplantation. ${ }^{5}$ Changes in number of Tregs have been reported in patients affected by AITD, suggesting their involvement in initiation and development of autoimmune thyroid disorders. ${ }^{6}$

A prevalent Th1-driven autoimmune response has been clearly recognized in $\mathrm{HT},{ }^{7}$ this supported by studies where the Th1-distinctive cytokines (IFN- $\gamma$ and IL-2) were measured in serum ${ }^{8}$ and in intrathyroidal lymphocytes ${ }^{9,10}$ of HT patients. Recently, the Th1/Th2 paradigm has been expanded by the discovery of a novel T-cell subset, Th17 cells, which produce IL-17, a pro-inflammatory cytokine not produced by either Th1 or Th2 CD4+ T cells. Th17 cells have recently been shown to play a major role in numerous AIDs that were previously thought to be Th1-dominant diseases, including AITD. ${ }^{11-14}$ Moreover, an imbalance of pro-inflammatory and tissue-destructive Th17 cells and tissue-protective Tregs has been confirmed in a number of tissue-inflammatory states, including AID. The central cytokine in this balance, on the basis of mouse data, may be IL-6, which skews immune responses towards Th17 or Th1 and away from Treg phenotypes. ${ }^{15}$
Along with IL-17, Th17 cells also produce IL-22. Both cytokines exert their effects on epithelial cells in various tissues and can be protective against infections, but also become pathological in several inflammatory diseases. ${ }^{16-18}$ IL-17 is largely pro-inflammatory and destructive. ${ }^{16}$ IL-22 exerts pro-inflammatory effects in synergy with IL-17, TNF- $\alpha$ and IFN- $\gamma$, but it also has a regenerative and protective effect on epithelial cells; thus IL-22 is regarded as an ambivalent cytokine. ${ }^{17-21}$ In addition to Th17 cells, a second Th cells population has been more recently identified as a major source of IL-22, so-called Th22 cells; however, Th22 cells do not secrete IL-17. ${ }^{18,19,22}$ These two T cell lineages share the T-cell Receptor (TCR) +, CD3+, CD4+, CCR6+ phenotype. The Th22 are CCR4+ and CCR10+. Th22 cells infiltrate the epidermis in individuals with inflammatory skin disorders and seem to be implicated in the pathogenesis of several AIDs, such as rheumatoid arthritis (RA), systemic lupus erythematosus (LES) and psoriasis. ${ }^{22,23}$ Thus, there is emerging evidence that IL-22, whatever the source (Th17 or Th22 or both), is differentially involved in the development of several AIDs, such as RA, LES, psoriasis, multiple sclerosis and Sjögren's syndrome. ${ }^{24-30}$ Moreover, IL-22 gene knockout or inhibition of IL-22 protein considerably ameliorates AID in murine models. ${ }^{31,32}$ Only one paper is available in the literature on the role of IL-22 in AITD. ${ }^{14}$

\section{MATERIALS AND METHODS}

\section{Patients and study design}

We enrolled 85 consecutive patients with overt or suspected thyroid disease referred to our outpatient clinic over a period of six months. All patients met the following criteria: 1 ) euthyroidism at the time of sampling; 2) no L-T4 therapy or drugs affecting thyroid function. In addition, age- and sex-matched control subjects $(n=25)$ were also recruited after providing a history to rule out current and past thyroid illness. None of the patients or control subjects had a history of neoplastic disease and symptoms or laboratory signs of inflammatory diseases (including non-thyroid AID), asthma and other allergic disorders, active infections, diabetes mellitus or kidney failure. Each subject received a careful medical evaluation, including recording of past and current medical history and physical examination. 
In all patients and control subjects we performed thyroid ultrasonography (US) and measured serum free thyroxine (FT4), free triiodothyronine (FT3), thyrotropin (TSH), thyroglobulin antibody ( $\mathrm{Tg}-\mathrm{Ab})$ and thyroid peroxidase antibody (TPO-Ab) levels. HT and goiter were diagnosed by clinical, laboratory and US criteria. Thus, HT was also diagnosed in thyroid autoantibody-negative patients who met US criteria for thyroiditis, that is, a heterogeneous echo-structure with diffuse or patchy hypoechogenicity. ${ }^{33-35}$ Other thyroid diseases which are associated with an echographic pattern of hypoechogenicity (i.e. silent or post-partum thyroiditis, subacute thyroiditis) were ruled out.

The study was approved by the local Ethics Committee. Informed consent was obtained from the patients and control subjects.

\section{Methods}

Peripheral blood samples were collected after overnight fasting from all the recruited patients and control subjects and the serum was stored at $-20^{\circ} \mathrm{C}$ for cytokine assay. Serum levels of IL-22 were measured by a quantitative enzyme immunoassay technique by using the IL-22 Quantikine ELISA Kit according to the manufacturer's instructions (R \& D System, Minneapolis, USA). A microplate reader (BioRad Laboratories, Model 550, Milan, Italy), capable of measuring absorbance at $450 \mathrm{~nm}$, was used to measure the intensity of color developed in each well. All assays were done in duplicate. The detection limit of the assay was $0.7 \mathrm{pg} / \mathrm{ml}$. Intra-assay and inter-assay CVs were less than $4.5 \%$ and $8.4 \%$, respectively.

Serum FT4, FT3 and TSH concentrations were measured by the immunoenzymatic method (commercial kits by Medical Systems, Genoa, Italy; normal values in our laboratory: $10.3-24.6 \mathrm{pmol} / \mathrm{L}$ and $2.7-6.45$ $\mathrm{pmol} / \mathrm{L}$ for FT4 and FT3, respectively; 0.4-4. $0 \mathrm{mU} / \mathrm{L}$ for TSH). Tg-Ab and TPO-Ab were measured by the corresponding immunoradiometric assay kit by DiaSorin (Saluggia, Italy); normal values are $<100$ $\mathrm{U} / \mathrm{mL}$ and $<10 \mathrm{U} / \mathrm{mL}$, respectively. The intra- or the inter-assay coefficients of variation, for all assays, were less than $5 \%$ and less than $10 \%$, respectively.

A real-time 2D apparatus (General Electric Healthcare, USA) with a 7.5-10 MHz linear transducer was used to perform thyroid US.

\section{STATISTICAL ANALYSIS}

Data are expressed as means \pm SD. Differences between three or more unpaired groups were analyzed by the Kruskal Wallis test and between two unpaired groups by the Mann-Whitney test to compare two groups. Correlation between two variables was evaluated with Spearman's rho. The level of statistical significance was always set at $\mathrm{p}<0.05$.

\section{RESULTS}

The characteristics of our study population are summarized in Table 1. On the basis of the clinical, US and laboratory evidence, the patients were subdivided into three study groups. Group A included 55 HT patients; group B (or non-HT patients with nodular goiter) consisted of 30 patients affected by nodular goiter without any evidence of HT, that is, with no positivity for serum $\mathrm{TgAb}$ and TPOAb and no thyroid hypoechogenicity at US. Finally, group C included 25 age- and sex-matched healthy control subjects, without clinical, US or biochemical evidence of thyroid disorders. As shown in Table 1, the three groups did not differ significantly. All patients and controls were euthyroid without having L-thyroxine therapy.

As shown in Figure 1 (panel A), there was a statistical difference between the three groups $(\mathrm{P}<0.001)$. HT patients showed significantly higher levels of serum IL-22 (group A, mean \pm SD: $42 \pm 34 \mathrm{pg} / \mathrm{ml}$; median: 33; range 10-145.8) in comparison with both non-HT patients with nodular goiter (group B, mean \pm SD: $18 \pm 15$ pg/ml; median: 12.5 , range 3.2-54.7; $\mathrm{P}<0.001$ ) and healthy controls (group $\mathrm{C}$, mean \pm SD: $20 \pm 13 \mathrm{pg} / \mathrm{ml}$; median: 18; range 5.37 - 42.7; $\mathrm{P}=0.014$ ) (Figure 1, panel A). Serum IL-22 levels did not differ in non-HT goitrous patients and in the healthy population $(\mathrm{P}=0.496)$ (Figure 1 , panel $\mathrm{A})$.

The 17 HT patients negative for thyroid autoantibodies displayed lower levels of IL-22 in comparison with $\mathrm{Ab}-\mathrm{Tg}$ and/or Ab-TPO positive patients (39 \pm 24 vs $44 \pm 38 \mathrm{pg} / \mathrm{ml}$ ), but this difference was not statistically significant $(\mathrm{P}=0.799)$ (Figure 1, panel $\mathrm{B})$. Again, IL-22 values in Ab-negative HT patients were significantly higher than in autoimmune diseases-free subjects, considering each group of patients (group B and $\mathrm{C}$, respectively, $\mathrm{P}=0.001$ and $\mathrm{P}=0.017$ ) (Figure 1, panel B). Furthermore, IL-22 values in Ab-positive 
Table 1. Clinical, biochemical and sonographic characteristics of the three groups of investigated subjects

\begin{tabular}{|c|c|c|c|c|}
\hline & $\begin{array}{c}\text { Group A } \\
\text { (HT patients) }\end{array}$ & $\begin{array}{c}\text { Group B } \\
\text { (Non-HT patients with nodular goiter) }\end{array}$ & $\begin{array}{c}\text { Group C } \\
\text { (Healthy controls) }\end{array}$ & \\
\hline Total no. of patient & 55 & 30 & 25 & \\
\hline \multicolumn{5}{|l|}{ Sex } \\
\hline male & 5 & 4 & 3 & \\
\hline female & 50 & 26 & 22 & \\
\hline Age, mean \pm SD (range) & $38 \pm 17(15-70)$ & $43 \pm 14(26-78)$ & $40 \pm 12(21-71)$ & $\mathrm{NS}^{\mathrm{a}}$ \\
\hline $\mathrm{TSH}(\mathrm{mIU} / \mathrm{L})^{*}$ & $2.1 \pm 1.1$ & $1.6 \pm 0.6$ & $1.8 \pm 0.7$ & $\mathrm{NS}^{\mathrm{a}}$ \\
\hline FT3 $(\mathrm{pmol} / \mathrm{L})^{*}$ & $4.6 \pm 0.7$ & $4.7 \pm 0.7$ & $4.2 \pm 0.9$ & $\mathrm{NS}^{\mathrm{a}}$ \\
\hline FT4 $(\mathrm{pmol} / \mathrm{L})^{*}$ & $16.8 \pm 3.24$ & $16 \pm 2.7$ & $15.3 \pm 2.5$ & $\mathrm{NS}^{\mathrm{a}}$ \\
\hline $\mathrm{Tg}-\mathrm{Ab}(\mathrm{U} / \mathrm{L})^{* \S}$ & $388.5(134-4000)$ & Absent & Absent & \\
\hline $\mathrm{TPO}-\mathrm{Ab}(\mathrm{U} / \mathrm{L})^{* \S}$ & $255(44-8070)$ & Absent & Absent & \\
\hline Thyroid volume $(\mathrm{ml})^{*}$ & $14.8 \pm 4.8$ & $20.87 \pm 4.1$ & $10.9 \pm 3.4$ & $\mathrm{NS}^{\mathrm{a}}$ \\
\hline
\end{tabular}

*Data are mean \pm SD, except Tg-Ab and TPO-Ab which are median (range). Normal values are specified under Material and Methods. The volume of thyroid lobes was calculated with the ellipsoid formula ( $\mathrm{p} / 6 \mathrm{x}$ height $\mathrm{x}$ width $\mathrm{x}$ dept, each diameter being expressed in centimetres).

${ }^{a}$ Comparison between means was made by the Student t-test.

$\S$ Of the $38 \mathrm{HT}$ patients who tested positive for Tg-Ab, TPO-Ab or both, $31(56 \%)$ were Tg-Ab +ve, $33(60 \%)$ were TPO-Ab +ve and $26(47 \%)$ were Tg-Ab +ve and TPO-Ab +ve. Consequently, 17/55 HT patients were negative for both Tg-Ab and TPO-Ab, despite the finding of the typical US features of chronic thyroiditis.

HT patients (i.e. excluding the Ab-negative patients) continued to be significantly higher than in the other two groups (group B and $\mathrm{C}$, respectively, $\mathrm{P}=0.002$ and $\mathrm{P}=0.034$ ) (Figure 1, panel B).

No significant correlation was found between IL-22 levels and serum levels of Ab-Tg and Ab-TPO in $\mathrm{HT}$ patients (rho $=-0.066$ and $-0.306 ; \mathrm{P}=0.693$ and $\mathrm{P}=0.062$, respectively) (Figure 2). The analysis was also performed separating the HT patients on the basis of the antibodies levels into strongly vs borderline antibody positive subjects. In accordance with the reference range of our laboratory, we set a cut-off value of 250 and $300 \mathrm{U} / \mathrm{mL}$ for $\mathrm{Ab}-\mathrm{Tg}$ and $\mathrm{Ab}-\mathrm{TPO}$, respectively, to separate the patients into
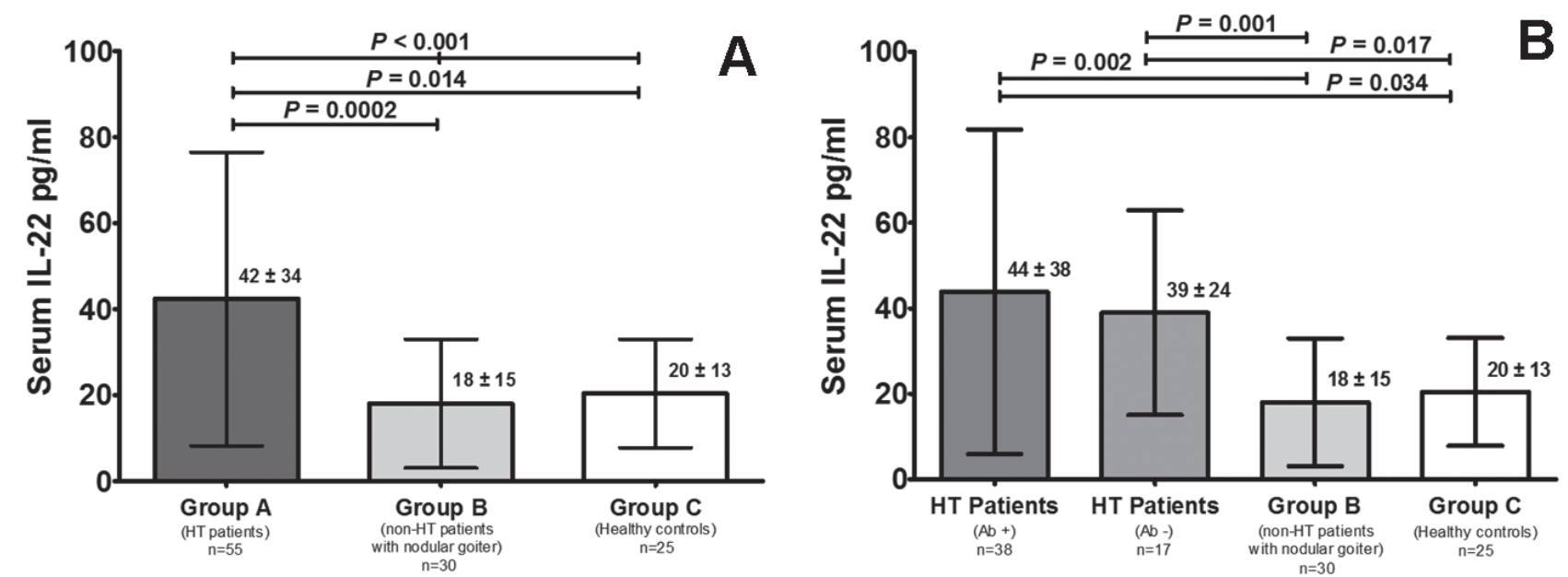

Figure 1. Panel A: serum levels of IL-22 in HT (Group A) and goitrous patients (Group B) and in control subjects (Group C). Panel $\mathrm{B}$ : group $\mathrm{A}$ was divided into $\mathrm{Ab}(\mathrm{Ab}-\mathrm{Tg}$ and/or $\mathrm{Ab}-\mathrm{TPO})$ positive and $\mathrm{Ab}$-negative patients. 

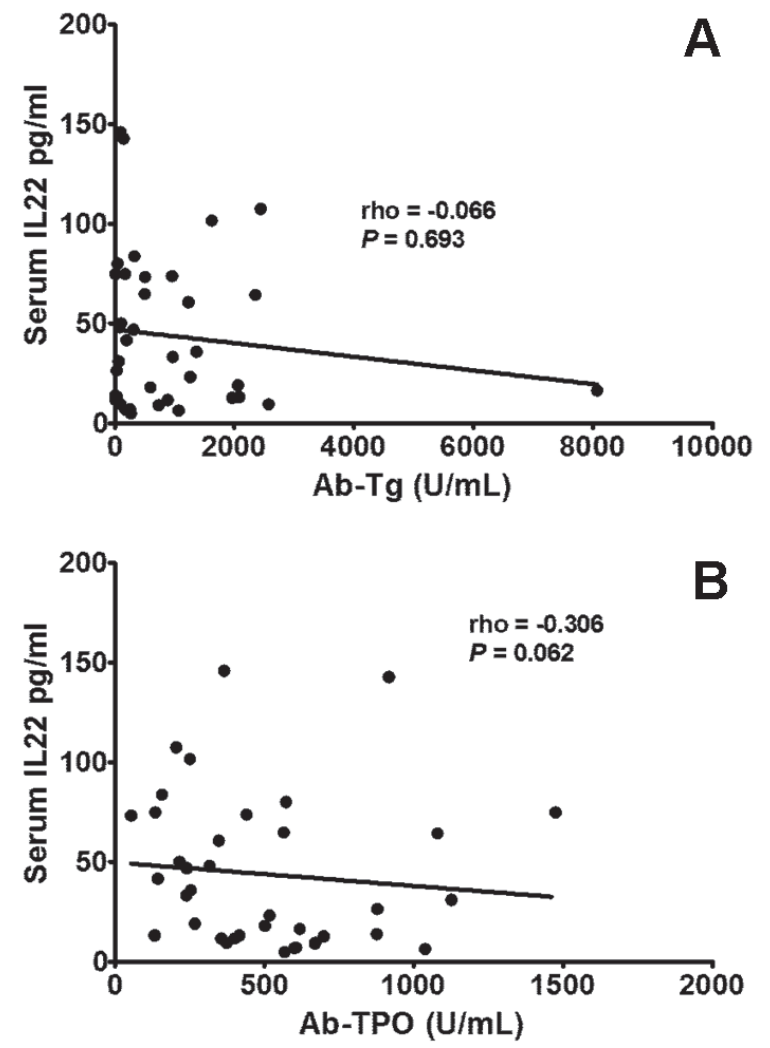

Figure 2. Correlation between IL-22 levels and serum levels of $\mathrm{Ab}-\mathrm{Tg}$ (panel A) and Ab-TPO (panel B) in HT.

the two groups. There was no correlation between IL-22 and Ab-Tg in strongly Ab-Tg positive or in borderline patients $(\mathrm{rho}=0.095$ and $0.165 ; \mathrm{P}=0.667$ and $\mathrm{P}=0.558$, respectively). Similarly, there was no correlation between IL-22 and Ab-TPO in strongly Ab-TPO positive or in borderline patients (rho = 0.161 and $-0.005 ; \mathrm{P}=0.618$ and $\mathrm{P}=0.981$, respectively). Furthermore, IL-22 values did not differ in HT patients positive for both Tg-Ab and TPO-Ab as compared to HT patients with positivity for only one of them.

No significant correlation was found between IL22 levels and TSH levels in HT patients (rho $=0.016$; $\mathrm{P}=0.908)$ and in goitrous patients (rho $=-0.051$; $\mathrm{P}=0.790)$.

\section{DISCUSSION}

IL-22, mainly synthesized by Th17 and Th22 cells, has an important role in the pathogenesis of several inflammatory and autoimmune conditions..$^{14,24-30}$ Recently, serum levels of IL-22 were reported to be increased in psoriasic arthritis as well as in RA and SLE and to be correlated with disease activity. ${ }^{25-29}$ Few data are available on serum IL-22 levels in AITD. Although several studies have evaluated the possible involvement of Th17 cells in AITD, ${ }^{11-14}$ only in one of them were serum levels of IL-22 measured. ${ }^{14}$ In this study, Figueroa-Vega and co-workers ${ }^{14}$ found enhanced levels of T cells synthesizing IL-17 and IL-22 in the peripheral blood of AITD patients, mainly in those with HT. Accordingly, serum levels of IL-22 were significantly higher in HT patients compared with both Graves' disease (GD) patients and healthy volunteers $(\mathrm{P}<0.05$ in both cases). In addition, a stronger expression of IL-17 and IL-22 was detected, by immunohistochemistry, in the thyroid glands of HT patients (although not the same patients in whom serum levels of cytokines were measured). Furthermore, they measured the serum levels of IL-6, IL-15 and IL-23 cytokines, which are known to promote Th17 differentiation, and found that IL-6 and IL-15 levels were increased, while serum levels of IL-23 tended to be higher in the sera of HT patients. Accordingly, an enhanced in vitro differentiation of $\mathrm{T}$ lymphocytes into Th17 cells induced by IL-6/IL-23 was observed. Thus, the authors concluded that Th17 cells may play a relevant role in the pathogenesis of HT, exerting their pathogenic effect through the release of IL-17 and IL-22. ${ }^{14}$

In the present study, we measured the serum levels of IL-22 in a large series of newly diagnosed, euthyroid HT patients and compared these values with those measured in euthyroid non-HT patients with nodular goiter as well as in healthy subjects without thyroid disease. All HT patients showed serum IL-22 levels significantly higher than those of non-HT patients with nodular goiter or healthy controls, but no differences were found between goitrous patients and healthy controls. These data suggest that IL-22, whether it is produced by $\mathrm{TH} 17$ or Th22 or both, plays some role in the development of HT. This is an interesting finding because HT is commonly considered to be a Th1-mediated disease. Our data strongly suggest that, as in the case of other autoimmune diseases like RA or multiple sclerosis, likewise in HT, subsets of activated lymphocytes other than Th1, such as the Th17 and/or Th22 cells, are involved in the mechanisms of inflammation and tissue damage. This is in line with data from the literature ${ }^{11-14}$ and possibly adds an additional 
factor for the understanding of the complex pathogenesis of AITD. Of note, our study group consisted of newly diagnosed HT patients at a very early stage of the disease. They were all euthyroid and thus were not receiving any treatment. Thus, our findings could reflect an early autoimmune deregulation or an early step in the natural course of HT.

The present results are in agreement with the evidence and hypotheses of our previous studies. ${ }^{36-38} \mathrm{We}$ have already demonstrated, by immunohistochemistry, a stronger expression of IL-6 in the thyroid glands of both GD and HT patients compared to goitrous patients and normal thyroid tissues obtained at autopsy. ${ }^{36,37}$ Moreover, in HT patients IL-6 expression was positively correlated with the grade of lymphocytic infiltration. ${ }^{37}$ In agreement with the immunohistochemical studies, we also found increased concentrations of IL-6 in sera of HT patients. ${ }^{38}$ Overall, our data suggest a role of IL-6 in the development of HT. In light of the new data on the role of Th17-Th22 in HT, it is reasonable to postulate that the intra-thyroidal IL-6 production/expression may induce IL-22 production by Th17 and Th 22 cells, similarly to what shown in the skin. ${ }^{39}$ Obviously, this extrapolation from peripheral blood to the intra-thyroidal environment requires experimental verification.

This study has demonstrated that IL-22 serum levels were increased in HT patients as compared to autoimmune diseases-free individuals. We could not correlate IL-22 serum levels with thyroid functional status because our patients were all euthyroid. However, no significant correlation was found between IL-22 and TSH levels in this series of patients. We tested whether IL-22 concentrations correlated with the levels of anti-thyroid autoantibodies, but no correlation was found. However, other studies on peripheral blood levels of cytokines and lymphocyte subsets in AIDT also failed to identify such a correlation. For instance, in an Indian study ${ }^{40}$ including 35 AITD patients and 10 healthy controls, serum IL-5 increased in both HT and GD patients compared to the controls. When the serum values of IL-5 were correlated with other parameters (T4, TSH and autoantibodies titre) within each group of GD or HT, no statistically significant correlation was found in any group. ${ }^{40}$ Nor was any correlation with $\mathrm{Ab}$ levels mentioned in the above cited study by Figueroa-Vega, including only 18 patients (13 HT, 5 GD). ${ }^{14}$

In summary, our study confirms the conclusion of other authors ${ }^{14}$ of the involvement of IL-22 producing cells in HT, our conclusions being based on a greater number of patients. Further investigation aimed at a better understanding of the relationship between IL-22 and the clinical course of HT should be performed in a large study population including subgroups of HT patients with both subclinical and overt hypothyroidism.

\section{REFERENCES}

1. Brent GA, Davies TF 2012 Hypothyroidism and thyroiditis. In: Melmed S, Polonsky KS, Larsen PR, Kronenberg HM (eds) $12^{\text {th }}$ Edition Williams Textbook of Endocrinology, Saunders, Philadelphia; pp, 423-456.

2. Benvenga S, Trimarchi F, 2008 Changed presentation of Hashimoto's thyroiditis in North-Eastern Sicily and Calabria (Southern Italy) based on a 31-year experience. Thyroid 18: 429-441.

3. Weetman AP, 2004 Cellular immune responses in autoimmune thyroid disease. Clin Endocrinol (Oxf) 61: 405-413.

4. Fountoulakis S, Tsatsoulis A, 2004 On the pathogenesis of autoimmune thyroid disease: a unifying hypothesis. Clin Endocrinol 60: 397-409.

5. Peterson RA, 2012 Regulatory T-cells: diverse phenotypes integral to immune homeostasis and suppression. Toxicol Pathol 40: 186-204.

6. Fountoulakis S, Vartholomatos G, Kolaitis N, Frillingos S, Philippou G, Tsatsoulis A, 2008 HLA-DR expressing peripheral $\mathrm{T}$ regulatory cells in newly diagnosed patients with different forms of autoimmune thyroid disease. Thyroid 18: 1195-1200.

7. Mazziotti G, Sorvillo F, Naclerio C, et al, 2003 Type-1 response in peripheral CD4+ and CD8+ T cells from patients with Hashimoto's thyroiditis. Eur J Endocrinol 148: 383-388.

8. Phenekos C, Vryonidou A, Gritzapis AD, Baxevanis CN, Goula M, Papamichail M, 2004 Th1 and Th2 serum cytokine profiles characterize patients with Hashimoto's thyroiditis (Th1) and Graves' disease (Th2). Neuroimmunomodulation 11: 209-213.

9. Paschke R, Schuppert F, Taton M, Velu T, 1994 Intrathyroidal cytokine gene expression profiles in autoimmune thyroiditis. J Endocrinol 141: 309-315.

10. Fisfalen ME, Palmer EM, Van Seventer GA, et al, 1997 Thyrotropin-receptor and thyroid peroxidase-specific $\mathrm{T}$ cell clones and their cytokine profile in autoimmune thyroid disease. J Clin Endocrinol Metab 82: 3655-3663.

11. Horie I, Abiru N, Nagayama Y, et al, 2009 T helper type 17 immune response plays an indispensable role for development of iodine-induced autoimmune thyroiditis in non-obese diabetic-H2h4 mice. Endocrinology 150 : 5135-5142. 
12. Nanba T, Watanabe M, Inoue N, Iwatani Y, 2009 Increases of the Th1/Th2 cell ratio in severe Hashimoto's disease and in the proportion of Th17 cells in intractable Graves' disease. Thyroid 19: 495-501.

13. Shi Y, Wang H, Su Z, et al, 2010 Differentiation imbalance of Th1/Th17 in peripheral blood mononuclear cells might contribute to pathogenesis of Hashimoto's thyroiditis. Scand J Immunol 72: 250-255.

14. Figueroa-Vega N, Alfonso-Pérez M, Benedicto I, Sánchez-Madrid F, González-Amaro R, Marazuela M, 2010 Increased circulating pro-inflammatory cytokines and Th17 lymphocytes in Hashimoto's thyroiditis. J Clin Endocrinol Metab 95: 953-962.

15. Afzali B, Lombardi G, Lechler RI, Lord GM, 2007 The role of T helper 17 (Th17) and regulatory T cells (Treg) in human organ transplantation and autoimmune disease. Clin Exp Immunol 148: 32-46.

16. Kolls JK, Khader SA, 2010 The role of Th17 cytokines in primary mucosal immunity. Cytokine Growth Factor Rev 21: 443-448.

17. Aujla SJ, Kolls JK, 2009 IL-22: a critical mediator in mucosal host defense. J Mol Med (Berl) 87: 451-454.

18. Eyerich S, Eyerich K, Cavani A, Schmidt-Weber C, 2010 IL-17 and IL-22: siblings, not twins. Trends Immunol 31: 354-361.

19. Witte E, Witte K, Warszawska K, Sabat R, Wolk K, 2010 Interleukin-22: a cytokine produced by T, NK and NKT cell subsets, with importance in the innate immune defense and tissue protection. Cytokine Growth Factor Rev 21: 365-379.

20. Sanjabi S, Zenewicz LA, Kamanaka M, Flavell RA, 2009 Anti-inflammatory and pro-inflammatory roles of TGF-b, IL-10, and IL-22 in immunity and autoimmunity. Curr Opin Pharmacol 9: 447-453.

21. Wolk K, Witte E, Witte K, Warszawska K, Sabat R, 2010 Biology of interleukin-22. Semin Immunopathol 32: 17-31.

22. Eyerich S, Eyerich K, Pennino D, et al, 2009 Th22 cells represent a distinct human $\mathrm{T}$ cell subset involved in epidermal immunity and remodeling. J Clin Invest 119: 3573-3585.

23. Yang XY, Wang HY, Zhao XY, Wang LJ, Lv QH, Wang QQ, 2013 Th22, but not Th17 Might be a Good Index to Predict the Tissue Involvement of Systemic Lupus Erythematosus. J Clin Immunol 33: 767-774.

24. Pan HF, Zhao XF, Yuan H, et al, 2009 Decreased serum IL-22 levels in patients with systemic lupus erythematosus. Clinica Chimica Acta 401: 179-180.

25. Ikeuchi H, Kuroiwa T, Hiramatsu N, et al, 2005 Expression of interleukin-22 in rheumatoid arthritis: potential role as a proinflammatory cytokine. Arthritis Rheum 52: 1037-1046.

26. Cheng F, Guo Z, Xu H, Yan D, Li Q, 2009 Decreased plasma IL22 levels, but not increased IL17 and IL23 levels, correlate with disease activity in patients with systemic lupus erythematosus. Ann Rheum Diseases 68: 604-606.

27. da Rocha Jr LF, Duarte AL, Dantas AT, et al, 2012 Increased serum interleukin 22 in patients with rheumatoid arthritis and correlation with disease activity. J Rheumatol 39:1320-1325.

28. Leipe J, Schramm MA, Grunke M, et al, 2011 Interleukin 22 serum levels are associated with radiographic progression in rheumatoid arthritis. Ann Rheum Dis 70: 1453-1457.

29. Mitra A, Raychaudhuri SK, Raychaudhuri SP, 2012 Functional role of IL-22 in psoriatic arthritis. Arthritis Res Ther 14: R65.

30. Pan HF, Li XP, Zheng SG, Ye DQ, 2013 Emerging role of interleukin-22 in autoimmune diseases. Cytokine Growth Factor Rev 24: 51-57.

31. Semerano L, Assier E, Boissier MC, 2012 Anti-cytokine vaccination: a new biotherapy of autoimmunity? Autoimmun Rev 11: 785-786.

32. Ke Y, Sun D, Jiang G, Kaplan HJ, Shao H, 2011 IL22-induced regulatory CD11b+ APCs suppress experimental autoimmune uveitis. J Immunol 187: 2130-2139.

33. Pedersen OM, Aardal NP, Larssen TB, Varhaug JE, Myking O, Vik-Mo H, 2000 The value of ultrasonography in predicting autoimmune thyroid disease. Thyroid 10: 251-259.

34. Rago T, Chiovato L, Grasso L, Pinchera A, Vitti P, 2001 Thyroid ultrasonography as a tool for detecting thyroid autoimmune diseases and predicting thyroid dysfunction in apparently healthy subjects. J Endocrinol Invest 24: 763-769.

35. Vejbjerg P, Knudsen N, Perrild H, et al, 2006 The association between hypoechogenicity or irregular echo pattern at thyroid ultrasonography and thyroid function in the general population. Eur J Endocrinol 155: 547-552.

36. Ruggeri RM, Villari D, Simone A, et al, 2002 Coexpression of interleukin-6 (IL-6) and interleukin-6 receptor (IL-6R) in thyroid nodules is associated with co-expression of CD30 ligand/CD30 receptor. J Endocrinol Invest 25: 959-966.

37. Ruggeri RM, Barresi G, Sciacchitano S, Trimarchi F, Benvenga S, Trovato M, 2006 Immunoexpression of the CD30 ligand/CD30 and IL-6/IL-6R signals in thyroid autoimmune diseases. Histol Histopathol 21: 249-256.

38. Ruggeri RM, Sciacchitano S, Vitale A, et al, 2009 Serum hepatocyte growth factor is increased in Hashimoto's thyroiditis whether or not it is associated with nodular goiter as compared with healthy non-goitrous individuals. J Endocrinol Invest 32: 465-469.

39. Zhang N, Pan HF, Ye DQ, 2011 Th22 in inflammatory and autoimmune disease: prospects for therapeutic intervention. Molecular and Cellular Biochemistry 353: 41-46.

40. Gopalakrishnan S, Sen S, Adhikari JS, Chugh PK, Sekhri T, Rajan S, 2010 The role of T-lymphocyte subsets and interleukin- 5 blood levels among Indian subjects with autoimmune thyroid disease. Hormones (Athens) 9: 76-81. 